\title{
Onset and End of the Rainy Season in South America in Observations and the ECHAM 4.5 Atmospheric General Circulation Model
}

\author{
Brant Liebmann,* Suzana J. Camargo, ${ }^{+}$Anji Seth, ${ }^{\text {José A. Marengo, }} \stackrel{\text { L Leila M. V. Carvalho, }}{ }$ \\ Dave Allured, $*$ Rong Fu, $* *$ and Carolina S. Vera ${ }^{++}$ \\ *NOAA-CIRES Climate Diagnostics Center, Boulder, Colorado \\ + International Research Institute for Climate and Society, Earth Institute at Columbia University, Palisades, New York \\ \# Department of Geography, University of Connecticut, Storrs, Connecticut \\ \& CPTEC/INPE, Cachoeira Paulista, Brazil \\ @ Department of Atmospheric Sciences, University of São Paulo, São Paulo, Brazil \\ **Earth and Atmospheric Sciences, Georgia Institute of Technology, Atlanta, Georgia \\ ++ Department of Atmospheric and Ocean Sciences, CIMA/UBA-CONICET, Buenos Aires, Argentina
}

(Manuscript received 14 October 2005, in final form 20 June 2006)

\begin{abstract}
Rainfall in South America as simulated by a 24-ensemble member of the ECHAM 4.5 atmospheric general circulation model is compared and contrasted with observations (in areas in which data are available) for the period 1976-2001. Emphasis is placed on determining the onset and end of the rainy season, from which its length and rain rate are determined.

It is shown that over large parts of the domain the onset and ending dates are well simulated by the model, with biases of less than 10 days. There is a tendency for model onset to occur early and ending to occur late, resulting in a simulated rainy season that is on average too long in many areas. The model wet season rain rate also tends to be larger than observed.

To estimate the relative importance of errors in wet season length and rain rate in determining biases in the annual total, adjusted totals are computed by substituting both the observed climatological wet season length and rate for those of the model. Problems in the rain rate generally are more important than problems in the length.

The wet season length and rain rate also contribute substantially to interannual variations in the annual total. These quantities are almost independent, and it is argued that they are each associated with different mechanisms.

The observed onset dates almost always lie within the range of onset of the ensemble members, even in the areas with a large model onset bias. In some areas, though, the model does not perform well. In southern Brazil the model ensemble average onset always occurs in summer, whereas the observations show that winter is often the wettest period. Individual members, however, do occasionally show a winter rainfall peak. In southern Northeast Brazil the model has a more distinct rainy season than is observed. In the northwest Amazon the model annual cycle is shifted relative to that observed, resulting in a model bias.

No interannual relationship between model and observed onset dates is expected unless onset in the model and observations has a mutual relationship with SST anomalies. In part of the near-equatorial Amazon, there does exist an interannual relationship between onset dates. Previous studies have shown that in this area there is a relationship between SST anomalies and variations in seasonal total rainfall.
\end{abstract}

\section{Introduction}

The purpose of the work presented here is to examine and compare statistics relevant to the South American rainy season in observations and an atmospheric

Corresponding author address: Brant Liebmann, NOAA-CIRES Climate Diagnostics Center, R/PSD1, 325 Broadway, Boulder, CO 80305-3328.

E-mail: Brant.Liebmann@noaa.gov

DOI: $10.1175 / J C L I 4122.1$

(C) 2007 American Meteorological Society general circulation model (GCM). The wet season is described by three parameters: its onset, end, and rain rate. All three are important from meteorological and societal perspectives.

From a meteorological perspective, onset and end represent a sudden change in a tropical atmospheric heat source, the addition or subtraction of which is known to alter both the large-scale (e.g., Simmons 1982; Silva Dias et al. 1983) and regional circulation (e.g., Horel et al. 1989; Figueroa et al. 1995; Lenters and 
Cook 1997). The rate determines the magnitude of that heat source.

In other parts of the world, especially India, timing of the rainy season has long been a subject of extreme interest, which is reflected in the literature (e.g., Saha and Saha 1980). Crops are planted relative to the anticipated onset of the rainy season. In South America, however, although crops are certainly planted to take advantage of the climatological rainy season, any added benefit to be gained by an accurate prediction of rainy season onset for a particular season is as yet unrealized.

Although the timing and quality of the wet season is of importance to agriculture in tropical South America, the ecosystem and forest is more sensitive to the length of the dry season (Sombroek 2001). Thus the ending date is of interest as well. The 2005 drought in the southwestern Amazon, most severe in at least $100 \mathrm{yr}$, resulted from an extended dry season. The drought severely affected the population downstream along the Amazon River main channel and its tributaries, the Solimões and Madeiras Rivers, that depend on river transportation, even though the wet season near the equator was near average.

The spatial and temporal variability of onset and end of the rainy season in South America has been the subject of some research. Kousky (1988) examined the spatially varying climatology of onset, using outgoing longwave radiation (OLR) as a proxy for rainfall. A pentad average of $240 \mathrm{~W} \mathrm{~m}^{-2}$ or below was considered to be deep convection. Onset was defined as occurring when deep convection began, provided that 10 of 12 preceding pentads were not convective, and 10 of 12 subsequent pentads were convective. The onset date was undetermined in extreme northwestern South America because the climatological OLR is always below the threshold for convection. From the equator to the southeast, however, Kousky (1988) concluded that onset proceeds from northwest to southeast from roughly August to October, with a later onset in eastern Brazil, although it is somewhat irregular in space. The end is more regular and proceeds to the northwest.

Horel et al. (1989) examined the interannual variability of onset of the South American rainy season, again using pentads of OLR. They defined $10^{\circ} \times 10^{\circ}$ boxes and determined the fraction of grid points (on a $2^{\circ} \times 2^{\circ}$ grid) with OLR less than $200 \mathrm{~W} \mathrm{~m}^{-2}$. Onset was defined as the first pentad on which the box with the maximum fraction of low OLR appeared in the Southern Hemisphere, provided it remained there for 25 days. A consistent definition was used for demise. Composites of 200-mb circulation from before and after onset revealed the development of the Bolivian High and a downstream trough corresponding to onset.
More recently, rainfall measurements from gauges throughout parts of South America have become available to the research community. Marengo et al. (2001) and Veiga et al. (2002) examined onset and end of the Amazon basin rainy season using pentads of observed rainfall computed from daily station records averaged onto grids. They defined onset (and end) analogous to Kousky (1988) and obtained similar results: onset proceeds from northwest to southeast. The rainy season withdraws from southeast to northwest but is slower than onset. When Marengo et al. (2001) adjusted the thresholds for onset to be higher, however, the sense of onset is reversed, although the pattern of withdrawal remains the same. Marengo et al. found an unexpectedly weak relationship between the length of the rainy season and total accumulation. There is also only a weak correlation between the date of onset or end and the total rainy season accumulation. A lack of correspondence between onset date and subsequent accumulation was confirmed by Janowiak and Xie (2003). Liebmann and Marengo (2001) found statistically relevant correlations between onset or demise and tropical sea surface temperature (SST) anomalies on some areas of the near-equatorial eastern Amazon. (Their study included the Amazon basin only.)

Liebmann and Marengo (2001), using gridded daily precipitation data, defined onset at a given point to be when accumulated precipitation begins to exceed its annual climatology. This definition is quite similar to that used in the present study. Using this definition, they found that the Amazon wet season begins first in the southeastern Amazon, and expands northward. The pentad-based definition of Janowiak and Xie (2003), also defined locally, produced the earliest onset over a region from $10^{\circ}$ to $15^{\circ} \mathrm{S}$, from which it progressed to the northeast and southwest. (They were unable to define onset in the northwest Amazon.) They noted that this sense of onset is quite different than the classic advance of onset in other parts of the globe.

The work presented here is an exploratory analysis of the ability of an atmospheric GCM to simulate the wet season in South America. The observed wet season is contrasted with that of the ECHAM 4.5 GCM, which was forced with observed SSTs. The onset and end of the wet season are computed and compared. These quantities allow the partition of the wet season into its length and rain rate. The relative importance of biases in the length of, and rain rate during, the wet season is estimated. The two are distinguished because they are almost completely independent and are associated with different physics. For example, onset, which is of course related to rainy season length, is associated with a decrease in convective inhibition energy (CINE), as 
shown by Fu et al. (1999), whereas once the rainy season begins, CINE is of minor importance.

The ability of the model to accurately simulate interannual variability may also depend on the proper partition of the wet season into length and rain rate. Both contribute substantially to interannual variability, but Liebmann and Marengo (2001) showed that in areas of the Amazon where calendar season rainfall anomalies are related to SST anomalies, the relationship seems to be through an association with onset or end, rather than through the wet season rain rate.

\section{Data}

Observed rainfall over South America is estimated from daily station records that have been averaged onto grids that exactly duplicate those of the model. Data from the 26-yr period 1976-2001 are used in this study, with the exception of 29 February, which is omitted from all calculations. One fewer year is used when the period in question spans two calendar years. Details of this dataset can be found in Liebmann and Allured (2005). Observed SSTs are those provided in the National Centers for Environmental Prediction-National Center for Atmospheric Research (NCEP-NCAR) reanalysis archives.

The model rainfall comes from matching years for 24 ensemble members of the ECHAM 4.5 (Roeckner et al. 1996) atmospheric GCM with a horizontal resolution of approximately $2.8^{\circ} \times 2.8^{\circ}$ latitude-longitude [triangular truncation at wavenumber 42 (T42)] and 19 vertical levels (hybrid sigma pressure coordinates). All of the integrations start in or before 1950 and extend until 2005. These integrations were performed at the International Research Institute for Climate and Society (IRI) and this model at this resolution is one of the models used for the IRI routine seasonal forecasts (Goddard et al. 2001, 2003). The ECHAM 4.5 was forced with observed monthly evolving SSTs. The output of the model is masked before display to match areas with rainfall observations in order to facilitate direct comparison with the observations.

The ECHAM 4.5 model was developed at the MaxPlanck-Institute for Meteorology in Hamburg, Germany. It evolved from the spectral weather prediction model of the European Centre for Medium-Range Weather Forecasts (ECMWF; Simmons et al. 1989). The ECHAM 4.5 model parameterization of cumulus convection is based on the bulk mass flux of Tiedtke (1989), modified according to Nordeng (1994). Detailed description of the ECHAM 4.5 GCM and its climatology is given in Roeckner et al. (1996). The interannual variability of the precipitation in the model is discussed in Moron et al. (2001) and Camargo et al. (2001).

\section{Results}

\section{a. Annual rainfall}

Figures $1 \mathrm{a}$ and $1 \mathrm{~b}$ show climatological annual total rainfall from observations and as an average over the 24 ensemble members. The maximum in the northwest Amazon of more than $3 \mathrm{~m} \mathrm{yr}^{-1}$ and the minimum in Northeast Brazil are both evident in the model. The southeastward extension of high precipitation values from the northwest Amazon maximum, known as the South Atlantic convergence zone (SACZ), is reproduced by the model. The SACZ, however, appears to extend erroneously southward into southern Brazil as the easternmost band of alternating high and low values whose contrast increases toward the mountains, while observed rainfall decreases monotonically to the west. The alternating bands of errors can be seen if the bias is plotted as a percent of the observed total (Fig. 1c), but the errors associated with this extension of the SACZ are quite small south of about $25^{\circ} \mathrm{S}$ because there is an observed maximum in southern Brazil. The banding is suspected to result from improper resolution of the Andes Mountains in this relatively courseresolution model.

Another problem area is in the vicinity of northern Brazil and French Guiana. The model Atlantic intertropical convergence zone (ITCZ) does not extend far enough to the west, as seen in the unmasked field (not shown), and thus there is a model minimum. The observations show a maximum with values about as high as those in the northwest Amazon.

\section{b. Onset of the rainy season}

A quantity "anomalous accumulation" is defined at each grid point over time as

$$
A(\text { day })=\sum_{n=1}^{\text {day }}[R(n)-\bar{R}],
$$

where $R(n)$ is the daily precipitation and $\bar{R}$ is the climatological annual daily average. The calculation can be started at any time, but in practice it is started 10 days prior to the beginning of the driest month and is summed for a year.

From (1), the beginning of the rainy season is defined as the day after the start of the longest period for which anomalous accumulation remains positive (relative to the day before the start). Thus, for the period whose beginning marks the start of the rainy season, the accumulation is above the annual mean accumulation. The end of the rainy season is defined as the day within that period on which anomalous accumulation reaches a maximum. This definition is almost identical to that proposed by Liebmann and Marengo (2001). 


\section{Annual Total Precipitation}
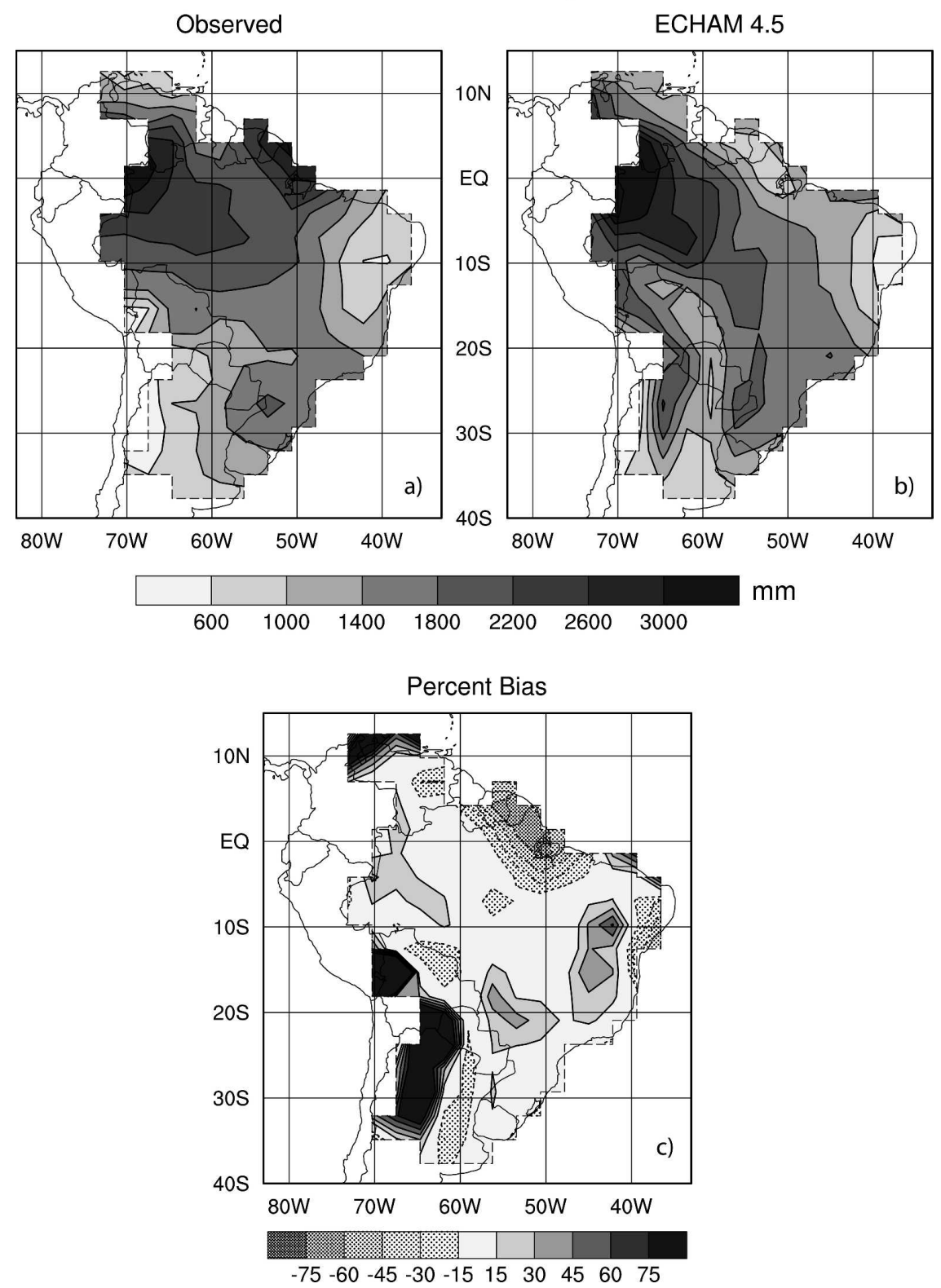

FIG. 1. Annual total precipitation, averaged for the years 1976-2000 on model grid. Dashed lines indicate data perimeter. (a) Observed values; (b) 24-member ensemble average of the ECHAM 4.5 model; and (c) model-observations expressed as percent of observed.

Figure 2 shows examples of anomalous accumulation curves. The dashed curve is calculated from observations for a single year in the southern Amazon basin, while the solid curve comes from model output at the same point for the same year. The observed and model annual climatologies can be seen to be quite similar, as during the dry season (centered on about 4 July) the negative slope of each is about the same (i.e., when it is dry the accumulation curve is reduced by the same amount each day). In general, the comparison of anomalous accumulation curves does not yield information about total rainfall, as the model and observations have different climatologies. At this particular point, however, since the climatologies are almost identical, it can be seen that for this particular rainy season more rainfall was recorded than was simulated by the chosen realization because the observed anomalous accumulation is larger.

In this particular year the observed onset occurs on 17 October and the simulated onset occurs on 18 Oc- 


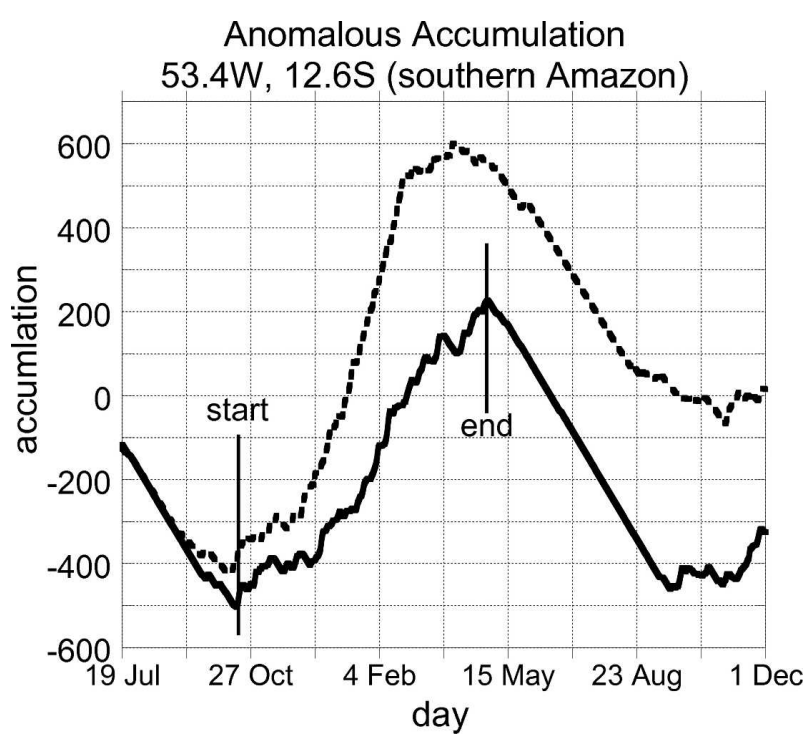

FIG. 2. Anomalous accumulation [computed from (1)] for a single year of observations (dashed curve) and a single model realization (solid curve). Vertical lines indicate the start and end dates of the model wet season.

tober (vertical line). In the 365 days beginning on 21 June (10 days before the start of the average driest month), these dates begin the longest period during which anomalous accumulation stays above that expected from the annual climatology. Although for the example shown there is a close correspondence between observed and simulated onset dates, there is no reason to expect such a correspondence unless onset at this point is controlled by SST anomalies.

The end of the rainy season is defined to occur when rainfall no longer exceeds its climatology, which of course occurs when the curve reaches its peak. For this example, the model ending (denoted by vertical line) is later than observed. It should be noted that at this location the model performs quite well (in a statistical sense) and onset and end are robustly defined because of the steady rainfall during the wet season and an almost complete lack of rain during the dry season, as evidenced by the nearly straight curves during and after the wet season.

The average starting dates of the observations and the ensemble are shown in Figs. 3a and 3b. Although the comparison is not exact because the climatologies of the observations and models are different, onset occurs with a rapid increase in rainfall, which is captured by the methodology. Qualitatively the maps are quite similar, but Fig. 3c, the difference, reveals an overall early model bias, and some areas with large discrepancies. South of $25^{\circ} \mathrm{S}$, near the equator in western Brazil, and in southern Northeast Brazil, the model bias is so large that model and observed onset occur in different seasons. Even though the onset bias is large in southern Brazil, the model annual total precipitation is close to that observed (Fig. 1c).

An interesting aspect of Figs. $3 a$ and $3 b$ is that they both indicate that, using the present definition, onset of the rainy season occurs first in the southern Amazon basin or father south and progresses northward. Seth et al. (2007) showed that Climate Prediction Center (CPC) Merged Analysis of Precipitation (CMAP) pentad estimates of precipitation (Xie et al. 2003) for the 1979/80 Amazon rainy season are consistent with the present climatology. That season was characterized by a rapid shift rather than a smooth transition from the Northern to Southern Hemisphere. The rapid transition observed by Seth et al. (2007) runs contrary to the broadly held belief that the rainy season progresses from northwest to southeast, from the climatological Northern Hemisphere summer maximum, across the equator and into the Amazon. Janowiak and Xie (2003) also found onset to progress toward the equator, and noted that this sense of progression is different than in the other monsoons of the world.

Figure 4 is similar to Fig. 3, except it shows the climatological ending dates. The direction of withdrawal in the observations and the ensemble is broadly consistent, progressing northward. The largest discrepancies in ending date (Fig. 4c) occur in southeast South America, eastern Brazil, and the northwest Amazon. These areas also have large discrepancies in onset date (Fig. 3c).

Figure 5a shows the bias in wet season length. It is usually positive, but often small. The wet season rain rate can easily be computed with knowledge of the length. Figure $5 \mathrm{~b}$ shows the average difference in the wet season daily rate (approximated as the rate for the first 45 days from each year's onset). The pattern is quite similar to the error pattern in the annual total precipitation.

A distinction is made between the wet season rain rate and length. They both can contribute to the bias in annual total rainfall, but they are expected to result from different processes. For example, Fu et al. (1999) showed that a moistening of the planetary boundary layer and a lowering of the temperature at its top, thereby reducing CINE, control the conditioning of the large-scale thermodynamics prior to onset. $\mathrm{Li}$ and $\mathrm{Fu}$ (2004) showed in their composite analysis that the main increase in convective available potential energy (CAPE) and reduction in CINE occur prior to rainy season onset, although in the tropical atmosphere, CAPE often exists in the absence of deep convection 


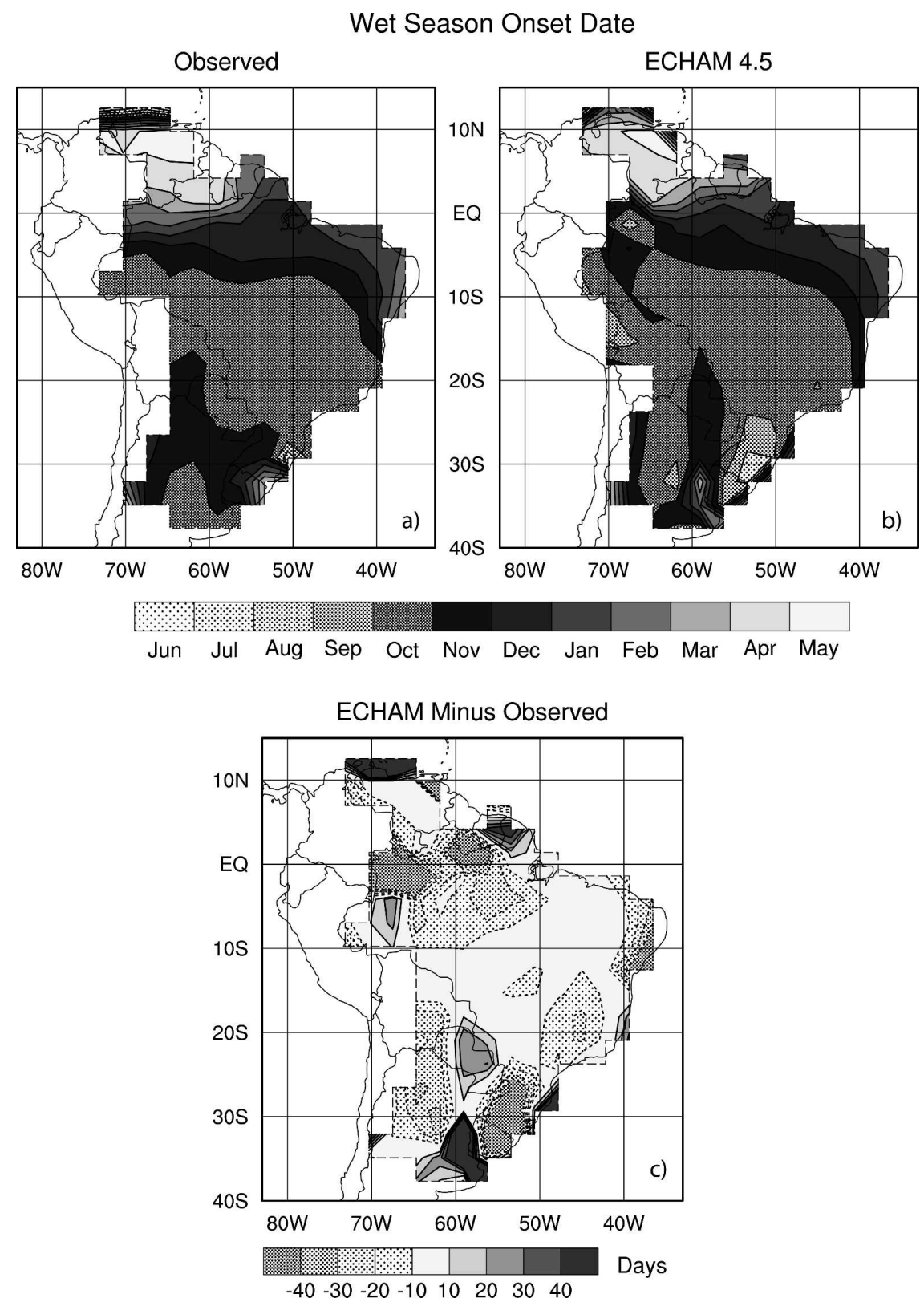

FIG. 3. Climatological onset date averaged from onset date for each year for (a) observations and (b) all ensemble members. (c) Average onset date of model-observations.

(e.g., Williams and Renno 1993). While there must be some level of CINE to overcome for rainfall to occur during the wet season, the rate is likely to be controlled by other aspects as well, such as the available moisture.

Biases in the wet season length and rain rate must contribute to biases in the annual total, unless they exactly cancel. The purpose of the following crude calculations is to determine the relative importance of the errors in length and rain rate in causing the model biases in total annual precipitation. This is accomplished by assuming two rainfall regimes, dry and wet. To de- termine the effect of length biases, the model climatology is adjusted by the following equation:

$$
A=\left(L_{\text {echam }}-L_{\text {obs }}\right) \times\left(R_{\text {wet }}-R_{\text {dry }}\right),
$$

where $A$ is the adjustment, $L_{\text {obs }}$ is the observed average length of the rainy season, $L_{\text {echam }}$ is the model ensemble average length, $R_{\text {wet }}$ is the model rainy season rain rate, defined as the average rate from onset until 44 days after onset, and $R_{\text {dry }}$ is the model dry season rate, defined as the average rate from 45 days before each year's onset, until the day before onset. 

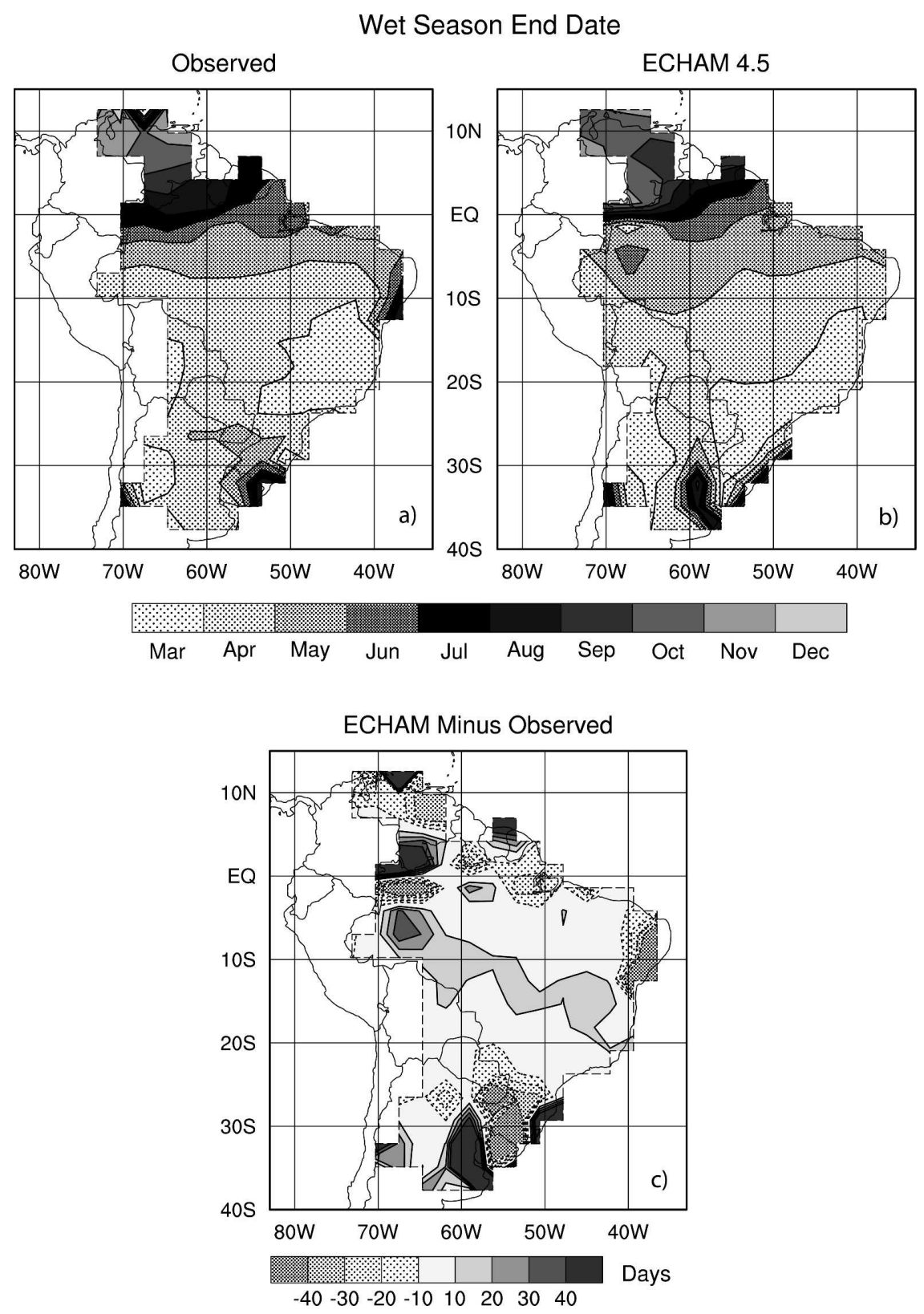

FIG. 4. Climatological ending date averaged from ending date for each year for (a) observations and (b) all ensemble members. (c) Average end date of model-observations.

Figure 6a shows the difference of the absolute difference in climatological rain totals prior to adjustment minus the absolute difference after adjustment. Much of the map is positive, indicating that, overall, the adjustment has resulted in a decreased absolute difference between the model and observations. On the other hand, there are also areas over South America where the adjustment results in an increased bias.

The change in model annual total by substituting the model with observed wet season rate with the observed rate is given by

$$
A=\left(R_{\text {obs }}-R_{\text {echam }}\right) \times L_{\text {echam }},
$$

where $R_{\mathrm{obs}}$ and $R_{\text {echam }}$ represent the observed and model wet season rates, and the other symbols are as in (2). Figure $6 \mathrm{~b}$ shows the absolute improvement by substitution of the observed wet rate. The corrections made by adjusting the rate are almost everywhere positive and larger than the corrections made from adjusting the length. While these simple adjustments of precipitation by roughly accounting for biases in length and rain rate certainly are not intended as a model 
Bias
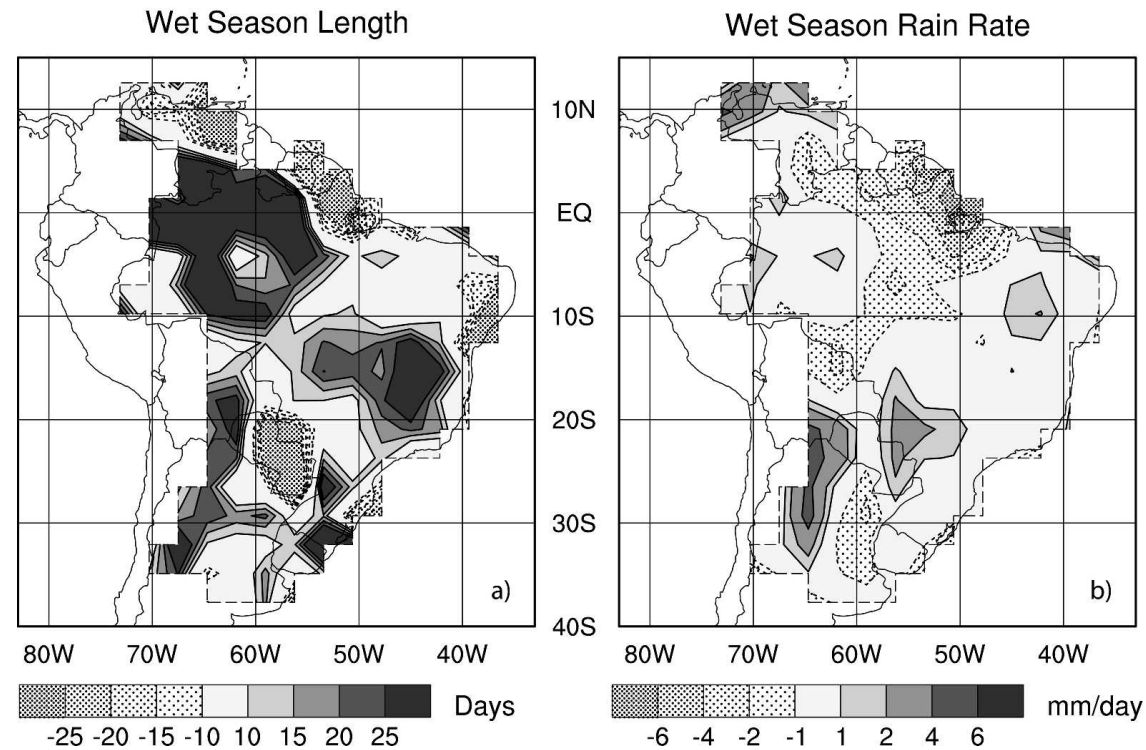

FIG. 5. Average observed-ensemble average rainy season (a) length and (b) rain rate.

"fix," they do suggest that gains in simulation climatology could be achieved by an improved estimation of the climatological onset, and even more so by improvement of the wet season rate.

The wet season length and rain rate contribute not only to biases in annual totals, but to their variations to interannual variability. Figures $7 \mathrm{a}$ and $7 \mathrm{~b}$ show the variance of observed annual (July-June) precipitation ex- plained by the length of the wet season and its rain rate. The length of the wet season and its rain rate are nearly uncorrelated. The wet season length explains little variance in the southern Amazon and northern La Plata basins, which includes the region affected by the SACZ. In this area, onset varies little from year to year, so it can account for little variation of rainfall. From the equator to $10^{\circ} \mathrm{S}$, however, upward of $40 \%$ is explained

\section{Absolute Improvement by Substitution}

Model Rate with Observed Length

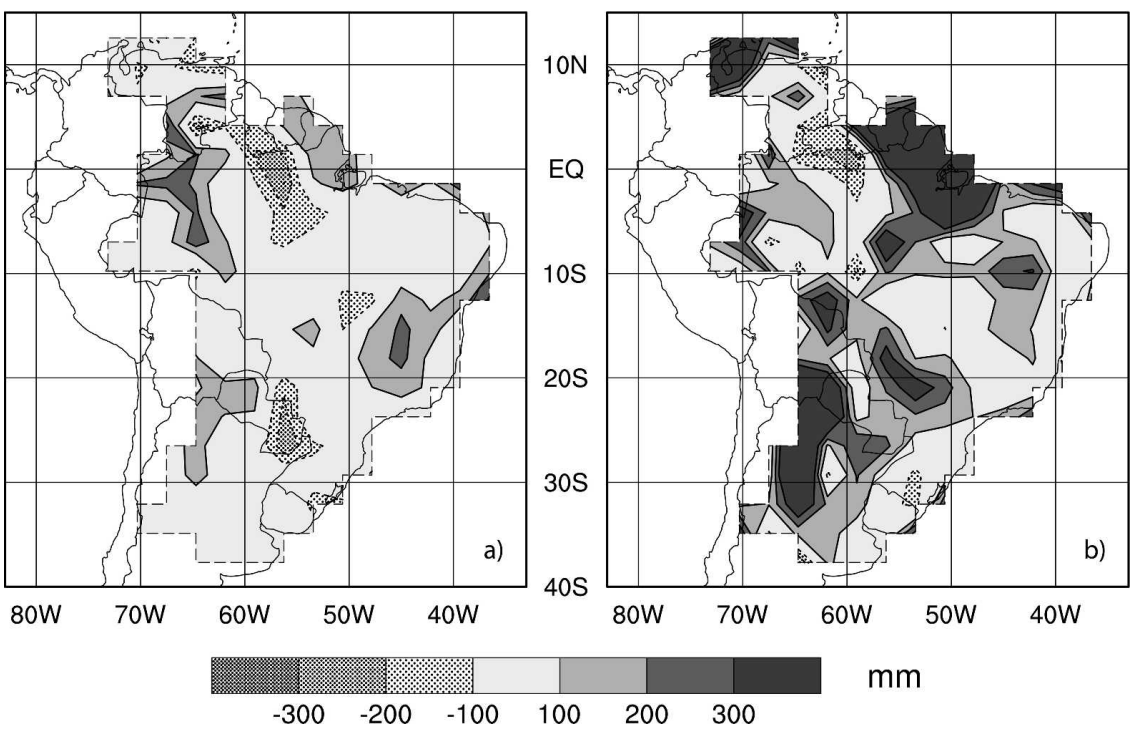

FIG. 6. Absolute improvement of model precipitation annual climatology by substitution of (a) observed length and (b) observed rate of wet season. Positive values indicate an improvement. 


\section{Observed Annual Total Variance Explained}

By Wet Season Length

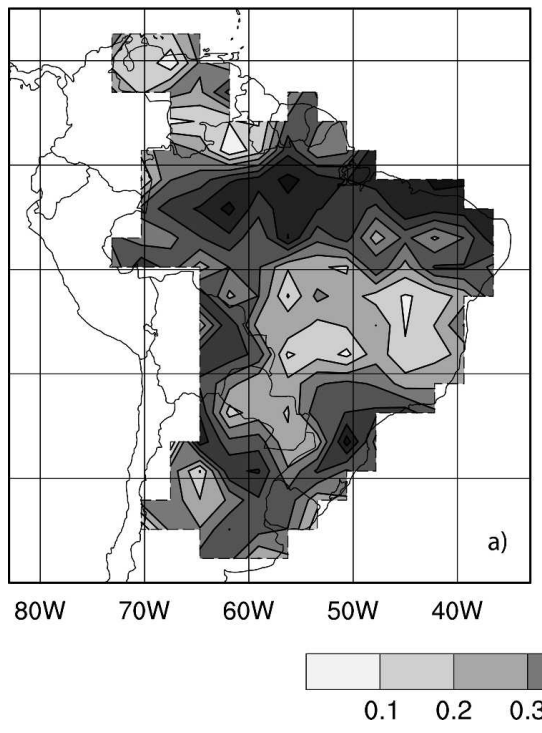

By Wet Season Rate

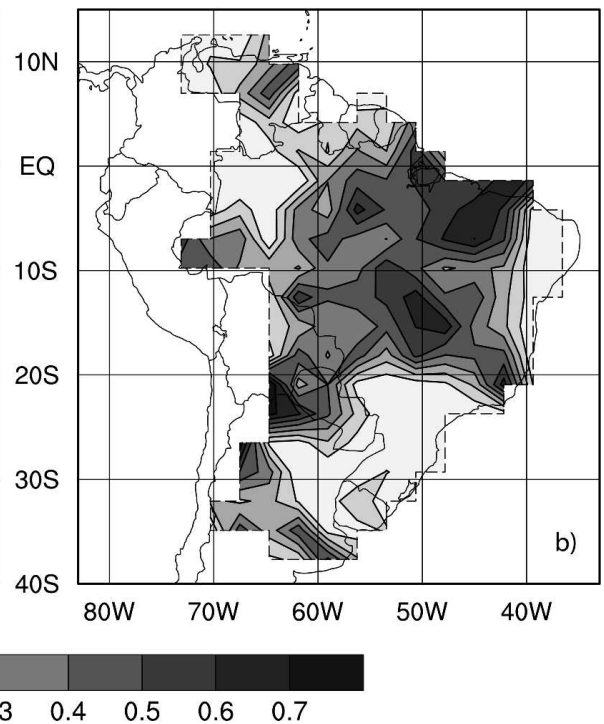

FIG. 7. Fraction of variance of observed annual total precipitation (summed from 1 July to 30 June) explained by variations in wet season (a) length and (b) rain rate.

at almost every grid point. In the same region that little variance is explained by wet season length, upward of $90 \%$ of the annual precipitation occurs during the wet season (Janowiak and Xie 2003). The length also explains substantial variability south of $20^{\circ} \mathrm{S}$, except for within Paraguay.

The variance of annual precipitation explained by the wet season rate, which is shown in Fig. $7 b$, is in marked contrast to that explained by the length. (The wet season rate is approximated as the daily average of the 45 days from onset.) The rate explains a large fraction of the variance in a band approximating the mean position of the SACZ, but overall somewhat less than does the length in the equator $-10^{\circ} \mathrm{S}$ band. The variance explained by rate is also low south of $20^{\circ} \mathrm{S}$, whereas that explained by the length is high.

\section{ECHAM Annual Total Variance Explained}

By Wet Season Length

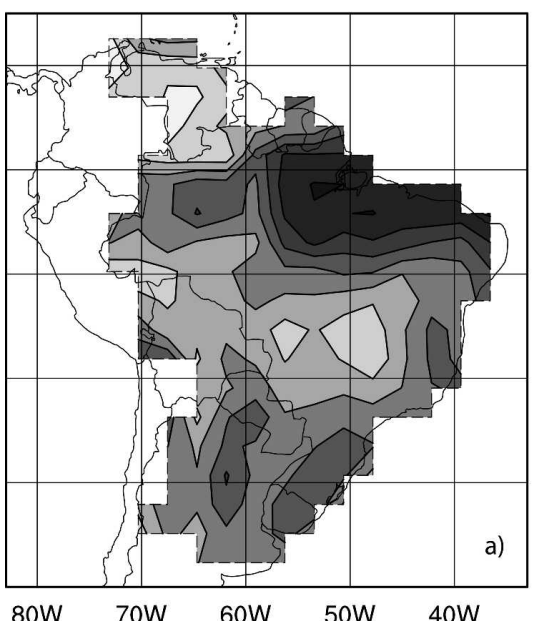

a)

$40 \mathrm{~S}$

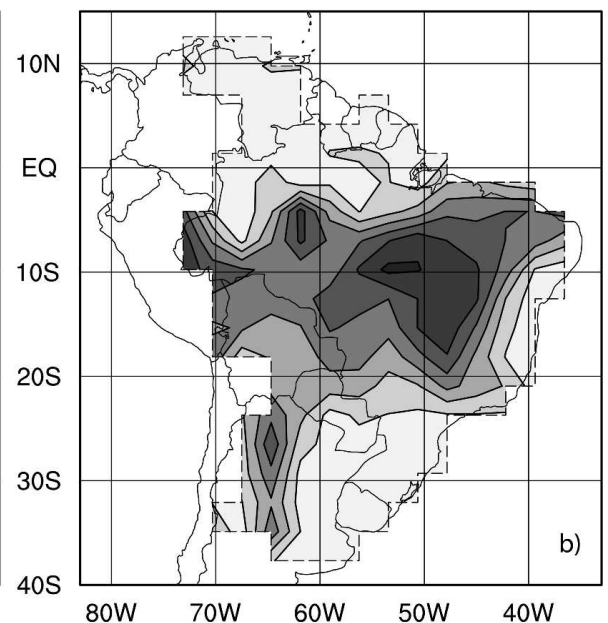

$$
\begin{array}{lllllll}
0.1 & 0.2 & 0.3 & 0.4 & 0.5 & 0.6 & 0.7
\end{array}
$$

FIG. 8. Same as in Fig. 7, but for ensemble average. 
Figure 8 is the model average equivalent to Fig. 7. The pattern quite closely resembles that of observations. Variations in length are important near the equator, yet play little role in the southern Amazon and SACZ. Like observations, these are the areas where variations in the rate assume the most importance.

Except for a region of SST influence in southeast Brazil, the only relationships between rainfall in South America and SST occur in the near-equatorial band, supporting the contention of Fu et al. (1999) that SST variations should be related to variations of wet season onset due to small variations in land surface temperature. Liebmann and Marengo (2001) found that in areas that exhibit correlations between total rainfall and SST, the connections are through the SST connection with onset or end rather than rain rate.

There is no expectation of an interannual correlation between observed and model onset except in those areas in which SST anomalies affect onset. Figure 9 shows the correlation between the observed and the ensemble average onset. In the areas with statistically relevant correlations (correlations greater than 0.5), there are known relationships between SST anomalies (i.e., Niño-3.4) and seasonal mean rainfall (e.g., Liebmann and Marengo 2001). On the other hand, there are areas, such as Northeast Brazil, that enjoy strong relationships with SST, and the model seasonal rainfall anomalies there are quite realistic (e.g., Goddard et al. 2001, 2003), yet there are no strong correlations between observed and model onsets.

\section{c. Regional comparisons}

There are many areas in the domain used in this study in which the model seems to perform quite well. For example, in the southern Amazon basin the observed and modeled annual totals are quite similar (Fig. 1 ), and the difference between the observed and simulated average onset and end dates are both within a few days of each other (Fig. 3 and Fig. 4). At $12.6^{\circ}$ S, $53.4^{\circ} \mathrm{W}$ (at which point examples of anomalous accumulation are shown in Fig. 2) the phasing of the annual cycle is in excellent agreement (Fig. 10a), and the monthly climatologies from June to November are nearly identical. Furthermore, the intermodel spread of the monthly climatology is negligible. Figure 10b shows that there is also little interannual variation in onset dates, and that the observed onset is almost always within the range of the individual member onsets.

There are, however, some areas in which there consistently appear large discrepancies between the observations and the model. One of these areas lies in southern Brazil. Although the annual totals are similar (Fig. 1), the observations indicate a local maximum of more
Observed vs. Model Onset: Correlation

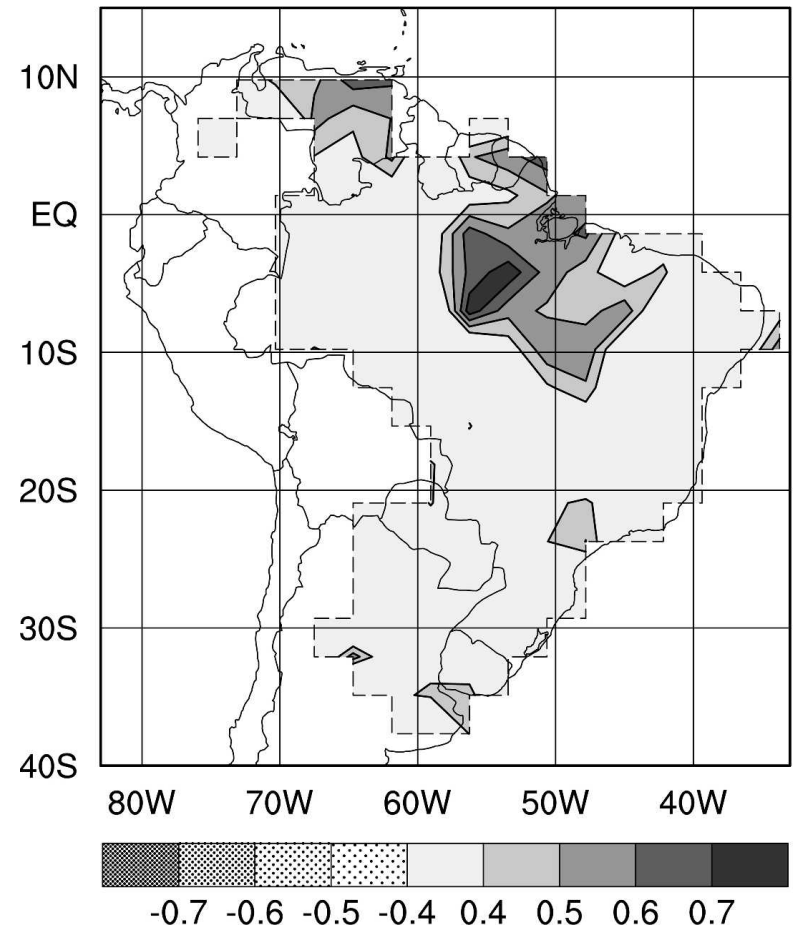

FIG. 9. Correlation between observed and ensemble average onset. Ensemble average is calculated as average of onset of each member.

than $1700 \mathrm{~mm}$, while the model shows an extension of the Amazon basin rainfall that does not appear in observations. In this area there are large biases in the average rainy season starting and ending dates (Figs. 3c and $4 \mathrm{c}$ ). As discussed below, part of the bias is the result of a shortcoming of the analysis technique, and part is due to a real difference between the observations and the model.

Figure 11a shows the monthly climatology in southern Brazil of the observations and the model. The observations reveal distinct summer and winter maxima in rainfall, and although the summer climatological average is larger than that during winter, the largest single monthly total occurred during winter. The winter peak is largely absent in the model.

The reason for the difference between observations and the model is that in 5 of the $25 \mathrm{yr}$, the observed summertime rainy season was quite short (by the present definition), whereas the model rainy season is much more regular. In each year the ensemble average onset date occurs in the summer (Fig. 11b). In the observations, the years with a short summertime rainy season are all followed by a wintertime rainy season that exceeded that of the previous summer. Thus the algorithm considers onset in these years to be quite late, 

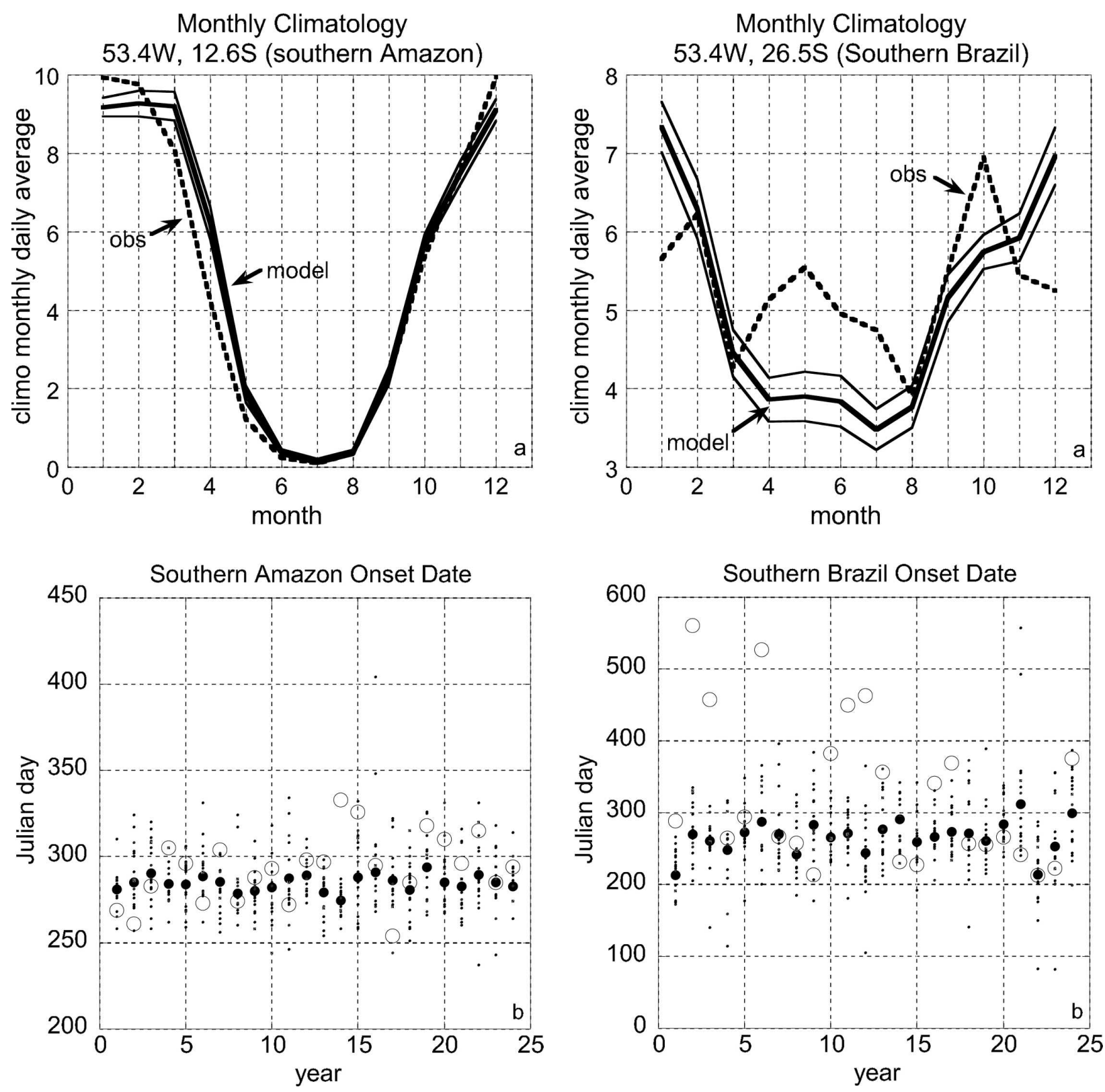

FIG. 10. Monthly daily average precipitation at $12.6^{\circ} \mathrm{S}, 53.4^{\circ} \mathrm{W}$ for observations and ensemble average. Thin curves on either side of ensemble mean represent $1 \mathrm{std}$ dev intermodel climatology. (b) Onset date for each year at same point for observations and average of each ensemble member. Open circles denote observed date, closed circles denote average over all ensemble members, and dots indicate onset for 18 ensemble members. Graphics limitations prevent showing each ensemble member.

as it begins counting near the end of July (10 days before the beginning of August, the driest month in the climatology). In one year, onset occurs in mid-July, which is defined as being extremely late. Had the algorithm started counting earlier, the average onset would have changed. If these five unusual years, in which on-

FIG. 11. Same as in Fig. 10, but for grid point at $26.5^{\circ} \mathrm{S}, 53.4^{\circ} \mathrm{W}$.

set occurs after the end of February, are removed from the calculation of average onset, the average becomes 7 October, just 14 days later than the model average. It is interesting that for a few of the individual members, onset occurs as late as is observed in the most extreme of years (Fig. 11b). These late model onsets (corresponding to a nearly absent summer rainy season) do not occur often enough to bring the average onset in line with the observed. Further complicating the statistics is that in some years in southern Brazil, there is no distinct break between the summer and winter rainy 

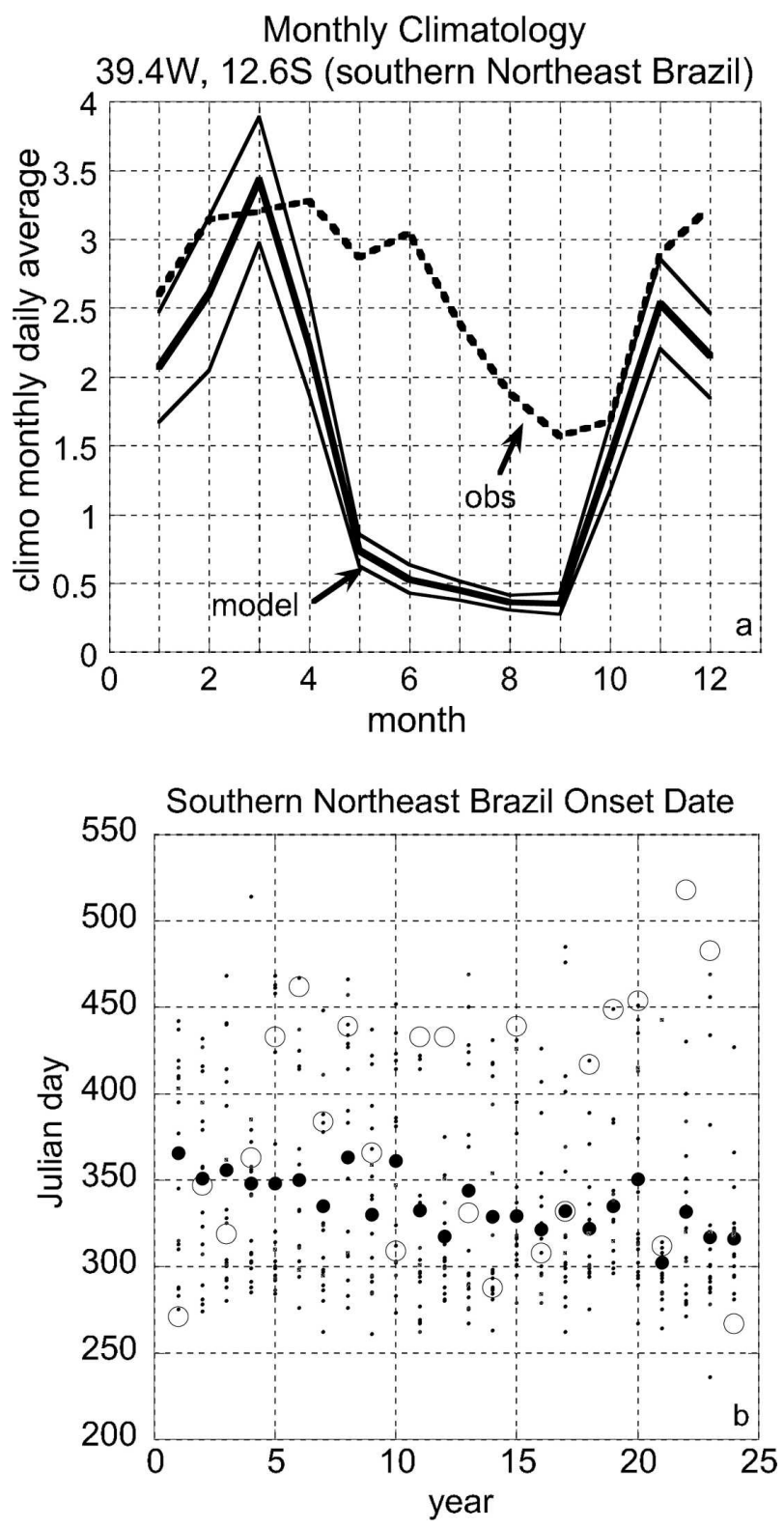

FIG. 12. Same as in Fig. 10, but for grid point at $12.6^{\circ} \mathrm{S}, 39.4^{\circ} \mathrm{W}$.

seasons, so the observed rainy season appears to last more than a year.

Another location with large differences between observed and model onset is along the coast of northeast Brazil. Although this area is relatively small, it is included because of the longstanding interest in northeast Brazil precipitation. The grid point of interest, located at $12.6^{\circ} \mathrm{S}, 39.4^{\circ} \mathrm{W}$ is not on the edge of the data void of the Atlantic. Edge points potentially are problematical because often fewer stations are averaged into these grid points.

Figure 12a is like Fig. 10a, except it shows the monthly climatology of the southern northeast Brazil point. The model annual total is substantially less than observed (Fig. 1c), owing primarily to a lack of a pronounced observed dry season at this location, in sharp contrast to the model. In the northern part of northeast Brazil, where observations show distinct wet and dry seasons, the model climatology simulates the observations quite well (not shown).

The interannual onset dates are shown in Fig. 12b. In about half of the years the observed onset is near the model average. The observed average onset date for those years (onset occurring before 1 February) is 19 November, close to the model average of 2 December. In the other half of the years, however, the observed average is 27 March, which is much later than the midJanuary average found in northern northeast Brazil.

Although there are many years in which observed onset occurs quite late with respect to the model average, they are nonetheless almost always within the range of the individual ensemble members. Unlike the observations, with a noticeable separation between early and late starts, there is no distinct separation in the model. The model starting dates, however, do tend to cluster toward the early end of the range; thus the average model starting date is earlier than that observed.

A third area in which there is a systematic difference in onset date is the northwest Brazilian Amazon. Here, observations reveal a maximum in May and a minimum during August, although the low values from August to November suggest a strong projection onto the annual harmonic (Fig. 13a). Note that the northwest Amazon receives more precipitation during its "driest" month than northeast Brazil receives during its wettest month. The model, on the other hand, produces a double maximum in rainfall, consisting of a distinct peak in April and a broad peak from October to December. This later model maximum nearly coincides with the observed annual minimum. Since the most dramatic rise in model precipitation occurs from July to September, while the observed precipitation begins increasing rapidly in November, there is a large systematic difference in onset, as reflected in Fig. 13b. The climatologies of the northwestern Amazon and Northeast Brazil are discussed in detail by Figueroa and Nobre (1990) and Marengo and Nobre (2001).

\section{Summary and discussion}

Variations and model biases of the wet season length and rain rate on South American annual total precipitation have been examined. Statistics of the rainy season are calculated for both observations and a 24member ensemble of the ECHAM 4.5 model, and the two are compared. 

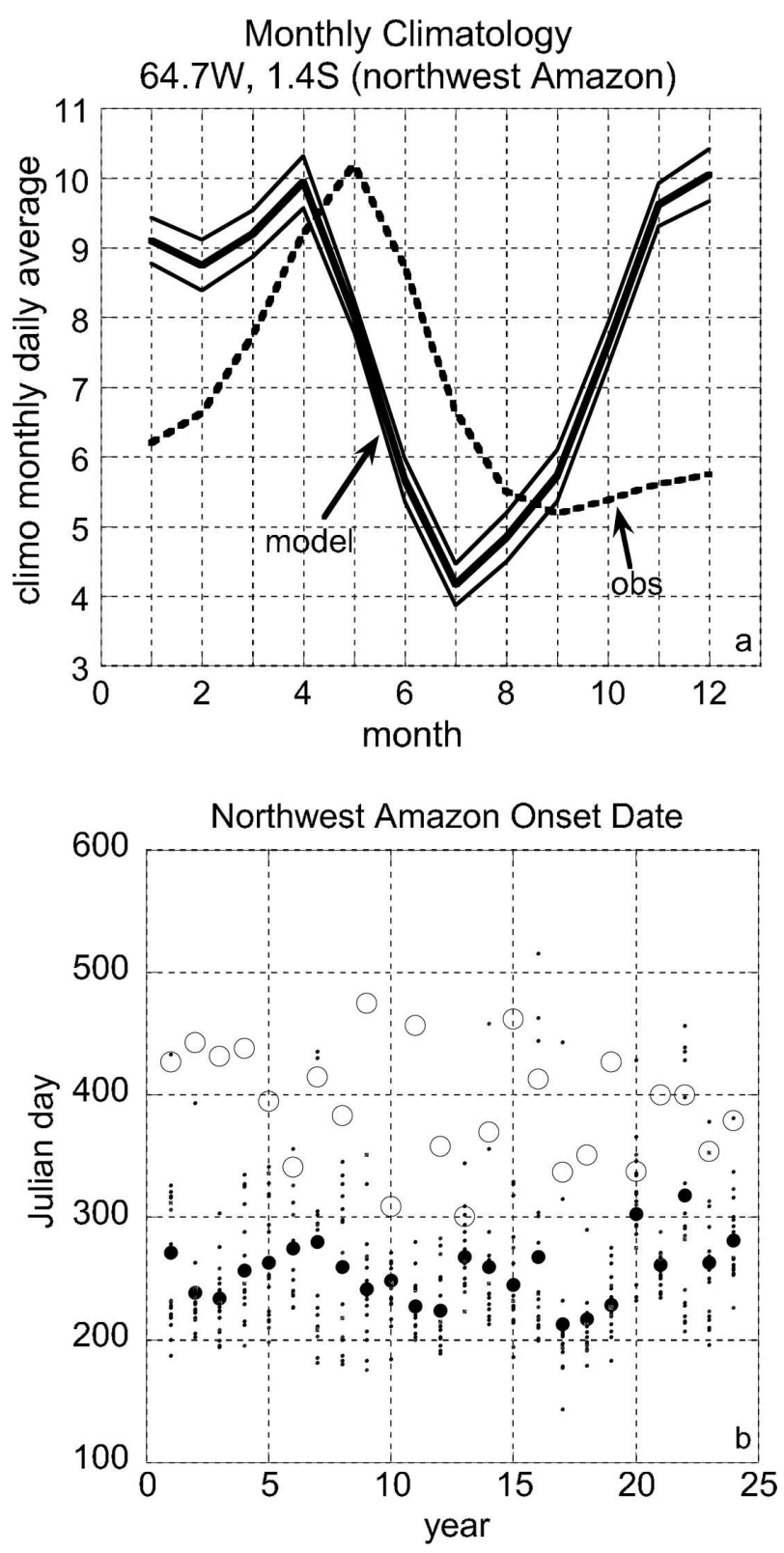

FIG. 13. Same as in Fig. 10, but for grid point at $1.4^{\circ} \mathrm{S}, 67.5^{\circ} \mathrm{W}$.

Onset and end are defined as the beginning and end of the longest period during which rainfall exceeds its annual climatology. One of the interesting aspects of this definition is that the rainy season progresses northward from the Southern Amazon, rather than from northwest to southeast as has been found in previous studies. The sense of onset seems to depend on whether the definition is based on a universal or local threshold. The universal threshold (e.g., Kousky 1988; Marengo et al. 2001) produces a poleward-progressing onset, while a local threshold (e.g., Liebmann and Marengo 2001;
Janowiak and Xie 2003) produces results consistent with the present study.

In general, the agreement between the climatological onset and end dates and the length of the rainy season between the observations and the ECHAM 4.5 ensemble is deemed to be quite good. Although the bias in length tends to be positive as a result of a model wet season that tends to start early and end late, over a large part of the domain the bias is less than 20 days.

The interannual wet season lengths and rain rates are also calculated. These two contributors to the annual total are separated because each are influenced by different processes and they are nearly independent. To understand their relative contribution to the bias in annual total precipitation, the model climatology is recalculated twice: once by replacing the model wet season length by that observed (and adjusting the total to account for changed lengths of precipitation at the dry and wet season rates), and also by replacing the average model wet season rate with the observed. Although a crude approximation, the results indicate that problems in the rain rate contribute more to the bias than do systematic biases in length.

Variations in total rainfall are not dominantly explained by variations in rate. It is shown that over most of the zone from the equator to $10^{\circ} \mathrm{S}$, variation of the rainy season length accounts for upward of $40 \%$ of the variance of the observed annual total. In the area affected by the SACZ, however, the variation of rate explains much more variance than does the variation of the length. The model partitions the explained variance quite well.

The fact that the length does not contribute much to variance in the vicinity of the SACZ may provide a clue as to why prediction skill is low in that area. Liebmann and Marengo (2001) found that those areas with an interannual relationship between rainfall and SST were characterized by a consistent relationship with onset or end (e.g., high totals and an early onset, both related to SST of the same sign). Fu et al. (1999) argued that onset would not be related to SST away from the equatorial zone. Since the wet season rate does not seem to be related to SST anomalies, areas in which interannual rainfall variability is dominated by that of the rate may enjoy increasing skill as land surface influences become better understood.

More subtly, model biases of timing can also affect interannual variability. For example, imagine a region in which the observed onset usually occurs in December, but the model has an early bias such that onset occurs in November. Thus if one is concerned with December-February (DJF) totals, even if the observed and model onset track perfectly, onset variations in the model will not contribute to variance of DJF totals. 
One of the goals of future work will be to quantify the extent that biases in the timing of the rainy season undermine the simulation of calendar season variability. In areas where onset or end timing is related to SST anomalies the bias may ruin predictive skill as well.

Acknowledgments. The authors would like to thank the NOAA Climate Program Office (Climate Prediction Program for the Americas) for their support. They also would like to thank the Max Planck Institute for Meteorology for making the ECHAM4.5 model accessible to IRI. We are indebted to Dr. B. Blumenthal for the IRI Data Library and to Dr. D. DeWitt for performing the ECHAM4.5 model integrations with support from Dr. X. Gong. This paper is funded in part by a grant/cooperative agreement from NOAA, NA050AR4311004. Thanks also to IAI/CRN055/ PROSUR, FAPESP 01-123165-01, and to PROBIO/ MMA/BIRD/GEF/CNPq from Brazil, for partially funding this research. JM was partially supported by the Brazilian Conselho Nacional de Desenvolvimento Científico e Tecnológico (CNPq). Finally, the suggestions of the anonymous reviewers aided in considerably improving the manuscript from its original form.

\section{REFERENCES}

Camargo, S. J., S. E. Zebiak, D. G. DeWitt, and L. Goddard, 2001: Seasonal comparison of the response of CCM3.6, ECHAM4.5, and COLA2.0 atmospheric models to observed SSTs. IRI Tech. Rep. 01/01, Palisades, NY, 68 pp.

Figueroa, N., and C. A. Nobre, 1990: Precipitation distribution over central and western tropical South America. Climanálise, 5, 36-40.

— - P. Satyamurty, and P. L. Silva Dias, 1995: Simulations of the summer circulation over the South American region with an eta coordinate model. J. Atmos. Sci., 52, 1573-1584.

Fu, R., B. Zhu, and R. E. Dickinson, 1999: How do atmosphere and land surface influence seasonal changes of convection in the tropical Amazon? J. Climate, 12, 1306-1321.

Goddard, L., S. J. Mason, S. E. Zebiak, C. F. Ropelewski, R. Basher, and M. A. Cane, 2001: Current approaches to seasonal to interannual climate predictions. Int. J. Climatol., 21, $1111-1152$.

— A. A. Barnston, and S. J. Mason, 2003: Evaluation of the IRI's "net assessment" seasonal climate forecasts: 1997-2001. Bull. Amer. Meteor. Soc., 84, 1761-1781.

Horel, J. D., A. N. Hahmann, and J. E. Geisler, 1989: An investigation of the annual cycle of convective activity over the tropical Americas. J. Climate, 2, 1388-1403.

Janowiak, J. E., and P. Xie, 2003: A global-scale examination of monsoon-related precipitation. J. Climate, 16, 4121-4133.

Kousky, V. E., 1988: Pentad outgoing longwave radiation climatology for the South American sector. Rev. Bras. Meteor., 3, 217-231.

Lenters, J. D., and K. H. Cook, 1997: On the origin of the Bolivian high and related circulation features of the South American climate. J. Atmos. Sci., 54, 656-678.
Li, W., and R. Fu, 2004: Transition of the large-scale atmospheric and land surface conditions from the dry to the wet season over Amazonia as diagnosed by the ECMWF Re-Analysis. $J$. Climate, 17, 2637-2651.

Liebmann, B., and J. A. Marengo, 2001: Interannual variability of the rainy season and rainfall in the Brazilian Amazon Basin. J. Climate, 14, 4308-4318.

- and D. Allured, 2005: Daily precipitation grids for South America. Bull. Amer. Meteor. Soc., 86, 1567-1570.

Marengo, J. A., and C. A. Nobre, 2001: General characteristics and variability of climate in the Amazon basin and its links to the global climate system. The Biogeochemistry of the Amazon Basin, M. E. McClaine, R. L. Victoria, and J. E. Richey, Eds., Oxford University Press, 17-42.

- B. Liebmann, V. E. Kousky, N. P. Filizola, and I. C. Wainer, 2001: Onset and end of the rainy season in the Brazilian Amazon Basin. J. Climate, 14, 833-852.

Moron, V., M. N. Ward, and N. Navarra, 2001: Observed and SST-forced seasonal rainfall variability across tropical America. Int. J. Climatol., 21, 1467-1501.

Nordeng, T. E., 1994: Extended versions of the convective parametrization scheme at the ECMWF and their impact upon the mean climate and transient activity of the model in tropics. ECMWF Tech. Memo. 206, Reading, United Kingdom, 25 pp.

Roeckner, E., and Coauthors, 1996: The atmospheric general circulation model ECHAM-4: Model description and simulation of present-day climate. Max-Planck Institute for Meteorology Tech. Rep. 218, Hamburg, Germany, 90 pp.

Saha, S., and K. Saha, 1980: A hypothesis on onset, advance and withdrawal of the Indian summer monsoon. Pure Appl. Geophys., 118, 1066-1075.

Seth, A., S. A. Rauscher, S. J. Camargo, J.-H. Qian, and J. S. Pal, 2007: RegCM3 regional climatologies for South America using reanalysis and ECHAM global model driving fields. Climate Dyn., 28, 461-480.

Silva Dias, P. L., W. H. Schubert, and M. DeMaria, 1983: Largescale response of the tropical atmosphere to transient convection. J. Atmos. Sci., 40, 2689-2707.

Simmons, A. J., 1982: The forcing of stationary wave motion by tropical diabatic heating. Quart. J. Roy. Meteor. Soc., 108, 503-534.

- D. M. Burridge, M. Jarraud, C. Girard, and W. Wergen, 1989: The ECMWF medium-range prediction models: Development of the numerical formulations and the impact of increased resolution. Meteor. Atmos. Phys., 40, 28-60.

Sombroek, W. G., 2001: Spatial and temporal patterns of Amazon rainfall. Ambio, 30, 388-396.

Tiedtke, M., 1989: A comprehensive mass flux scheme for cumulus parameterization in large-scale models. Mon. Wea. Rev., 117, 1779-1800.

Veiga, J. A., J. A. Marengo, and V. B. Rao, 2002: A influencia das anomalies de TSM dos oceanos Atlantico e Pacifico nas chuvas do moncao da America do Sul. Rev. Bras. Meteor., 17, 181-194.

Williams, E., and N. Renno, 1993: An analysis of conditional instability of the tropical atmosphere. Mon. Wea. Rev., 121, 21-36.

Xie, P., J. E. Janowiak, P. A. Arkin, R. Adler, A. Gruber, R. Ferraro, G. J. Huffman, and S. Curtis, 2003: GPCP pentad precipitation analyses: An experimental dataset based on gauge observations and satellite estimates. J. Climate, 16, 2197-2214. 